\title{
SOLUBILIZED CHITOSAN BIOPOLYMERS FOR SEQUESTRATION OF ORGANIC ACIDS IN AQUATIC ENVIRONMENTS AFTER BIODEGRADATION IN A CONSTRUCTED WETLAND TREATMENT SYSTEM
}

\author{
Mohamed H. Mohamed ${ }^{1}$, Chukwuemeka Ajaero ${ }^{2,4}$, Dena W. McMartinn ${ }^{2,3}$, Kerry M. Peru ${ }^{4}$, \\ Vanessa Friesen ${ }^{5}$, Monique Simair ${ }^{5}$, John V. Headley ${ }^{4 * *}$, Lee D. Wilson $^{1 *}$ \\ ${ }^{1}$ Department of Chemistry, University of Saskatchewan, 110 Science Place, Saskatoon, SK., \\ S7N $5 C 9$ \\ ${ }^{2}$ Faculty of Engineering and Applied Science, University of Regina, 3737 Wascana Parkway, Regina, \\ SK, Canada, S4S OA2 \\ ${ }^{3}$ Department of Civil, Geological \& Environmental Engineering, University of Saskatchewan, \\ Saskatoon, SK, S7N 5A9 \\ ${ }^{4}$ Water Science and Technology Directorate, Environment and Climate Change Canada, 11 \\ Innovation Boulevard, Saskatoon, SK S7N 3H5, Canada \\ ${ }^{5}$ Alexo Environmental Group, 104-411 Downey Road, Saskatoon, SK S7N 4L8, Canada
}

(Received: August 2018 / Revised: October 2018 / Accepted: November 2018)

\begin{abstract}
Pristine chitosan was dissolved in two different respective aqueous acids, namely acetic acid (AcA) and hydrochloric acid $(\mathrm{HCl})$. The respective acid solutions were used as media to associate with naphthenic acid fraction compounds (NAFCs) from raw oil sands process water (R-OSPW) contaminants and constructed treatment wetland systems OSPW (CWTS-OSPW) samples. The results revealed selective removal of NAFCs and lyotropic effects due to variable counterion binding of chloride versus acetate with the ionized NAFCs (carboxylate species).
\end{abstract}

Keywords: Chitosan; Hofmeister series; Naphthenic acids; Oil sands process water; Wetland

\section{INTRODUCTION}

The development of oil sands ores has resulted in the production of large volumes of oil sands process-affected water (OSPW), which in turn, poses a concern for nearby aquatic systems (Kelly et al., 2010). OSPW is acutely and chronically toxic to a variety of aquatic organisms (Clemente \& Fedorak, 2005) because it contains naphthenic acids (NAs), which are mainly associated with the toxicity of OSPW (Headley \& McMartin, 2004; Morandi et al., 2015). NAs are generally identified as a complex mixture of aliphatic and alicyclic monocarboxylic acids with the general formula $\mathrm{C}_{\mathrm{n}} \mathrm{H}_{2 \mathrm{n}+\mathrm{Z}} \mathrm{O}_{2}$, where $\mathrm{n}=$ number of carbons, $\mathrm{Z}=$ hydrogen deficiency, by the formation of rings (Headley \& McMartin, 2004). However, the application of highresolution analytical methods that employ Orbitrap-mass spectrometry (MS) and Fourier transform ion cyclotron resonance MS (FT-ICR-MS) has shed more light on the composition of OSPW to include oxidized NAs $\left(\mathrm{O}_{\mathrm{x}}\right.$; where $\left.\mathrm{x} \geq 3\right)$ and sulfur- and nitrogen-containing species $\left(\mathrm{NO}_{\mathrm{x}}, \mathrm{SO}_{\mathrm{x}}\right.$; Headley et al., 2009; Barrow et al., 2010; Grewer et al., 2010). In a broad sense, the aforementioned compounds are generally referred to as NA fraction compounds (NAFCs; Headley et al., 2016). As a consequence of the toxicity of OSPW, there is restriction on their

\footnotetext{
*Corresponding author's email: lee.wilson@usask.ca, Tel. +1-306-9662961, Fax. +1-306-9664730

**Corresponding author's email: john.headley@canada.ca, Tel. +1-306-9755746, Fax. +1-306-9755143

Permalink/DOI: https://doi.org/10.14716/ijtech.v9i6.2301
} 
release, and therefore, they are kept in large-scale tailings containment sites (Giesy et al., 2010). OSPW confined in storage containment sites requires further treatment of potentially toxic components before release of contained water to the aquatic environment (Limited, 2014; Hughes et al., 2017). This situation has led to innovative technologies and treatment strategies for OSPW remediation. Many treatment processes for OSPW remediation have been applied. Some of these technologies include conventional and advanced oxidation processes, membrane filtration technology, biological treatments, adsorption technology, and constructed wetland treatment systems (CWTS) (Rodgers \& Castle, 2008; Pramanik, 2016). CWTS are receiving great attention because they are feasible, economical, and ecologically viable technology for the improvement of the quality of wastewater that have found extensive application for the treatment of a variety of contaminants in different wastewaters (Kadlec \& Wallace, 2008). The removal of organic contaminants in CWTS is accomplished by the synergy of plants, soil, and hydrology, providing habitat and targeted reaction conditions for beneficial microorganisms (Rodgers \& Castle, 2008; Haakensen et al., 2015; Valipour \& Ahn, 2016). It is generally acknowledged that the removal processes of most contaminants in CWTS are performed by microbial processes (Faulwetter et al., 2009). The advancement of the technology of CWTS has led to potential application of diverse designs and operational conditions to maximize treatment efficiency. One of the more recently documented studies monitored the feasibility of OSPW treatment in a non-aerated wetland treatment system (Rodgers \& Castle, 2008); the work demonstrated that the wetland system was effective for the transformation of NAFCs in OSPW (Ajaero et al., 2018). Furthermore, past studies have shown that bio-persistent fractions of OSPW-NAFCs remain after treatment (Haakensen et al., 2015). The post-treatment of OSPW to completely oxidize the remaining fractions is essential for further improving the treatments. Therefore, a combination of CWTS and other post-treatment processes may be valuable for the ultimate reclamation of OSPW (McQueen et al., 2016).

Polysaccharide-based sorbents and their modified forms are considered inexpensive alternative materials for hazardous wastewater treatment, where such sorbent have been under investigation and development (Crini, 2005). Wilson and coworkers (2014) reviewed the utility of such modified materials for the sequestration of NAFCs from OSPW, along with studies of other biopolymer adsorbents (Mohamed et al., 2011; Mohamed et al., 2013; Mohamed et al., 2015a; Udoetok et al., 2016). In particular, we reported on the use of modified chitosan ( $\mathrm{CH})$ sorbent materials in the form of pellets that were water-insoluble for the controlled removal of NAFCs and other species in OSPW. The aim of this research was directed at further improvements to the methods for monitoring NAFCs after treatment in a CWTS (Haakensen et al., 2015; Mohamed et al., 2017). We concluded that the use of such chitosan pellets (CPs) without crosslinking are more suitable as solid-phase extractants (SPEs) for sample cleanup and analytical monitoring. A key feature of CPs to serve as suitable SPE materials was evidenced by the ability to sequester NAFCs, ultraviolet (UV)-active species, and the presence of various metal ion species, such as calcium and sodium, for the treatment wetland samples (Ajaero et al., 2018).

To improve on previously reported chitosan-based SPEs and their sorption properties in solidsolution systems that contain NAFCs, the use of $\mathrm{CH}$ in its dissolved form is proposed (Mohamed et al., 2015a; Mohamed et al., 2017). The enhanced adsorption properties of $\mathrm{CH}$ in homogeneous systems is understood due to the key importance of surface area and hydration effects, as revealed for chitosan flocculant systems in water treatment (Renault et al., 2009; Bhalkaran \& Wilson, 2016). The underlying hypotheses of this study are outlined as follows: $i$ ) solubilized forms of chitosan in aqueous acid will enhance its sequestration efficiency and molecular selectivity toward NAFCs, and ii) the role of biopolymer hydration effects and counterion binding of chitosan impart uptake selectivity due to lyotropy, as described by the 
Hofmeister effect (Hofmeister, 1888; Jungwirth \& Cremer, 2014). These hypotheses were tested by the study reported herein on the adsorption properties of chitosan in acidified homogeneous media with NAFC systems by varying the counterion species (chloride versus acetate) of chitosan. The improvements in the biopolymer association of chitosan with NAFCs is further demonstrated by switching the hydration character of the ammonium functional groups from the glucosamine units of $\mathrm{CH}$ by selection of acids with variable counterions (chloride and acetate), as reported in the present work.

\section{EXPERIMENTAL}

\subsection{Materials}

Chitosan was obtained from the POS BIO-Sciences Pilot Plant Corp (Project 2300) at the University of Saskatchewan (Saskatoon, Saskatchewan). Glacial acetic acid (AcA), hydrochloric acid $(\mathrm{HCl})$, acetonitrile, ammonium hydroxide, and 8 dram vials (screw thread with polyvinyl-faced pulp-lined closure) were obtained from Fisher Scientific (Ottawa, Ontario). Two-milliliter ( $\mathrm{ml}$ ) high-performance liquid chromatography (HPLC) amber vials with screw-cap perforated Teflon-lined septa were obtained from Canadian Life Science (Edmonton, Alberta). Raw OSPW (R-OSPW) and five types of treated wetland OSPW (CWTSOSPW; 2B, 4B, 6B, 8B, and 10B) were provided by Environment and Climate Change Canada (Saskatoon, Canada). The pilot-scale CWTS study was carried out at the greenhouse facilities of Contango Strategies Ltd. (Saskatoon, Saskatchewan). The temperature in the greenhouse facility was kept at $22^{\circ} \mathrm{C}$ from 7 am to $7 \mathrm{pm}$ and $16^{\circ} \mathrm{C}$ from $7 \mathrm{pm}$ to 7 am throughout the experiment. Each system was fed with OSPW uninterruptedly at a rate of $20 \mathrm{ml} / \mathrm{min}$ with FMI ${ }^{\circledR}$ QG 400. The outflow samples were collected in 500-ml plastic containers and kept in a refrigerator at $4{ }^{\circ} \mathrm{C}$ before analysis. The OSPW was supplied by a local industry in July 2015 from the Muskeg River Mine external tailings facility at the Shell Lease site north of Fort McMurray, which has been under ownership and operation of Canadian Natural Resources Ltd. (CNRL) since June 1, 2017.

\subsection{Sample Preparation and Analysis}

One gram of chitosan was dissolved in two different solvents $(100 \mathrm{ml})$, namely $1 \mathrm{M} \mathrm{HCl}(a q)$ and $1 \mathrm{M}$ AcA $(a q)$. Different concentrations of chitosan, in the range of 20-1,000 ppm, were added to $25 \mathrm{ml}$ of raw and various treated OSPW samples. The mixtures were incubated for 24 $\mathrm{h}$, followed by centrifuging and extraction of the resulting water using a reported method employing a weak anion exchange (WAX) SPE material (Ajaero et al., 2017). The extracted samples were analyzed using negative-ion electrospray ionization high-resolution MS (ESIHRMS) according to a similar methodology to that described in a previous study (Mohamed et al., 2015a).

\section{RESULTS AND DISCUSSION}

As described above, homogeneous aqueous solutions of chitosan were examined to study the adsorption properties of the native biopolymer in aqueous acidic media with NAFCs, where the acid additive $\left(\mathrm{HCl}\right.$ or $\left.\mathrm{CH}_{3} \mathrm{COOH}\right)$ was varied to ascertain the role of counterion (chloride versus acetate) effects on the adsorption properties of chitosan. Outlined below are results that describe the adsorption properties of chitosan using variable acid dopants in the presence of naphthenate mixtures derived from treated and untreated OSPW employing electrospray MS to measure the residual naphthenates in aqueous solution in the adsorption process of chitosan under variable experimental conditions.

\subsection{Sequestration of NAFCs}

The resulting mixture of solubilized chitosan in $\mathrm{HCl}(a q)$ is shown in Figure 1 (left), where the chitosan biopolymer precipitates out and decolorizes the R-OSPW, where it appears to improve 
with increasing chitosan concentration. Based on the visual observation, it can be inferred that NAFCs undergo phase separation upon association with chitosan, in agreement with the sorption isotherm shown in Figure 1 (right). The phase separation could be due to the differences in the initial solution $\mathrm{pH}$ of solubilized chitosan (acidic) and OSPW (weakly basic; $\sim \mathrm{pH} 7.9$ ).
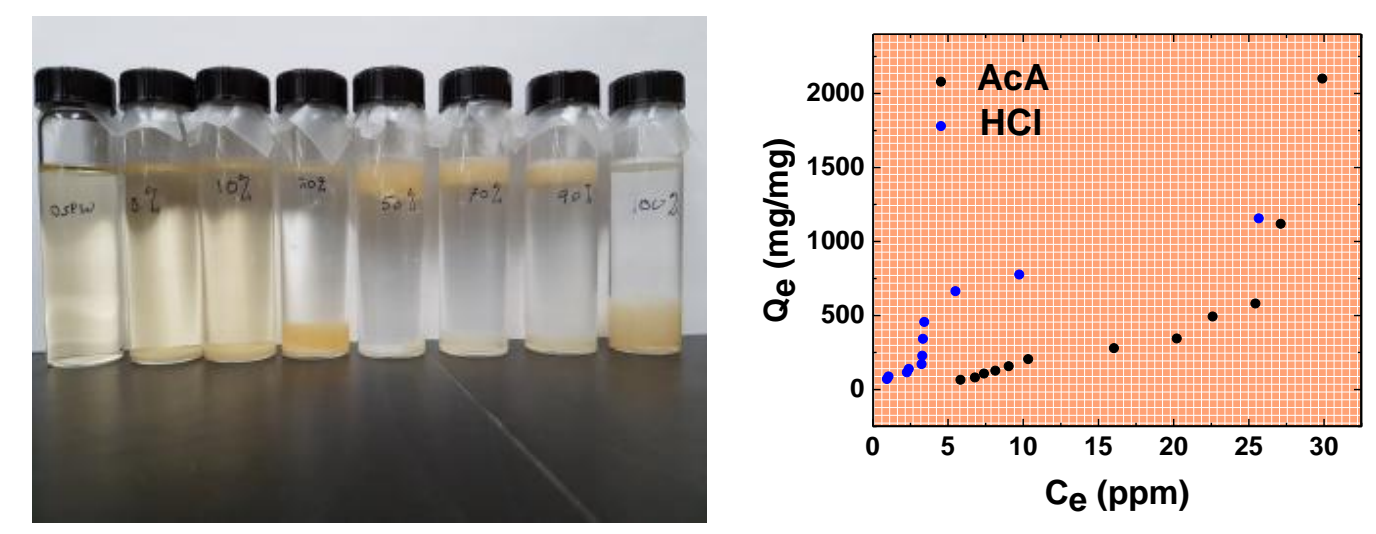

Figure 1 Left panel: vials of oil sands process water (OSPW) incubated with chitosan dissolved in aqueous hydrochloric $(\mathrm{HCl})$ after $24 \mathrm{~h}$. Right panel: Sorption isotherms of OSPW incubated with chitosan dissolved in aqueous $\mathrm{HCl}$ and acetic acid (AcA)

The isotherm results were generated by plotting the amount of NAFCs sorbed per unit weight of chitosan $\left(\mathrm{Q}_{\mathrm{e}}\right)$ under equilibrium conditions against the free (residual) NAFCs remaining in the aqueous solution that contained NAFCs. Chitosan dissolved in $\mathrm{HCl}(a q)$ achieved partial solubility during its preparation, where this form of chitosan had higher overall uptake of NAFCs relative to the chitosan sample that was dissolved in AcA. The difference in uptake for chitosan in each type of acid media paralleled the trend in counterion binding with the protonated amine sites of chitosan. In addition, the solubility of chitosan due to counterion effects that are in agreement with the relative hydration character of the anions, as described by the trend in the Hofmeister series for such anions. In the case of ionized chitosan in $\mathrm{HCl}(a q)$, the $\mathrm{Cl}^{-}$counterions associated with the protonated amine sites can readily undergo exchange (swapping) upon exposure to NAFCs $\left(\mathrm{RCOO}^{-}\right.$, where $\mathrm{R}=$ aliphatic or alicyclic moiety) in their carboxylate (ionized) form. The foregoing is understood according to the greater counterion binding of $\mathrm{RCOO}^{-}$over $\mathrm{Cl}^{-}$counterions with the protonated amine sites of chitosan. In contrast to the chloride $\left(\mathrm{Cl}^{-}\right)$counterions in $\mathrm{HCl}(a q)$, chitosan is associated with the acetate $\left(\mathrm{CH}_{3} \mathrm{COO}^{-}\right)$ counterion when dissolved in aqueous AcA. In $\mathrm{CH}_{3} \mathrm{COOH}(a q)$, chitosan does not favor counterion swapping with NAFCs $\left(\mathrm{RCOO}^{-}\right)$since the acetate counterions are in excess relative to the $\mathrm{RCOO}^{-}$and the similar hydration properties of these carboxylate anions do not favor anion exchange, on the basis of thermodynamic considerations. The stability of the complex formed between $\mathrm{CO}_{2}$ and chitosan in dimethyl sulfoxide (DMSO) show parallel agreement with the chitosan/carboxylate anion complexes described herein (Eftaiha et al., 2016). The secondary contribution of interfacial interactions due to hydrophobic effects that may occur upon phase separation of chitosan and NAFCs cannot be ruled out. In contrast to solid-solution adsorption processes reported for chitosan-NAFC systems (Mohamed et al., 2015a, Mohamed et al., 2017), it is noteworthy that the dissolved form of chitosan has a significantly greater uptake (ca. 1,000fold) over that of chitosan in its solid form reported for heterogeneous adsorption processes in aqueous solutions (Mohamed et al., 2015a). This was expected because the surface charge and accessibility of the active adsorption sites of chitosan are inferred to be greater for the solubilized form (Kong et al., 2018). In turn, the enhanced hydration effects and surface accessibility favor the kinetic and thermodynamic adsorption properties for the chitosan-NAFC system in homogeneous media. 
The sorption properties of chitosan in the two aqueous acid solutions $\left(\mathrm{HCl}(a q)\right.$ and $\mathrm{CH}_{3} \mathrm{COOH}$ $(a q)$ ) were examined in each respective acid solution that contained wetland treated samples. The uptake of OSPW by chitosan is observed to be variable for chitosan according to the variable removal (\%) reported for dissolution of chitosan in each type of acid solution. In the case of $2 \mathrm{~B}-10 \mathrm{~B}$, the levels of removal $(\%)$ for the NAFCs were 76.3, 86.1, 78.3, 78.6, and $87.5 \%$ for the chitosan system in aqueous AcA. By comparison, greater removal was noted for chitosan in $\mathrm{HCl}(a q ; 94.7,98.9,95.6,98.7$, and 96.3\%) for 2B-10B. Similar to R-OSPW, chitosan in the presence of $\mathrm{HCl}(a q)$ had an overall greater uptake of NAFCs, in agreement with the counterion binding trends described above.

The mechanism of NAFC uptake is illustrated in Scheme 1 below. It is noted that the $\mathrm{pK}_{\mathrm{a}}$ of chitosan used in this work (data not shown) is 6.2, according to a potentiometric titration that agrees with other related studies for chitosan (Roberts, 1992; Mahaninia \& Wilson, 2017). Thus, the use of conditions in aqueous media that lie below $\mathrm{pH} 6$ led to protonation of the glucosamine groups of chitosan. In contrast, the $\mathrm{pK}_{\mathrm{a}}$ for naphthenate components $\left(\mathrm{O}_{2}, \mathrm{O}_{3}\right.$, and $\mathrm{O}_{4}$ species) in OSPW resides across a range of $\mathrm{pK}_{\mathrm{a}}$ value between 3.5-7 (Armstrong et al., 2009; Huang et al., 2015). In typical OSPW environments, the media are somewhat alkaline (ca. $\mathrm{pH} \approx 8$; Allen, 2008); thereby resulting in ionization of the main $\mathrm{O}_{2}$ species of OSPW to yield the ionized carboxylate NAFCs. Upon addition of OSPW to the solubilized chitosan (in the acidic media), the carboxylates are protonated, where two possible interactions may occur: $i$ ) hydrophobic interaction of the $\mathrm{R}$ group with the apolar domains of chitosan ( $c f$. Scheme 1) and ii) ion-dipole interactions between the protonated glucosamine groups of chitosan ( $c f$. Scheme 1) and $-\mathrm{OH}$ from the carboxylate in NAFCs. These interactions are anticipated to contribute to the observed phase separation described above.
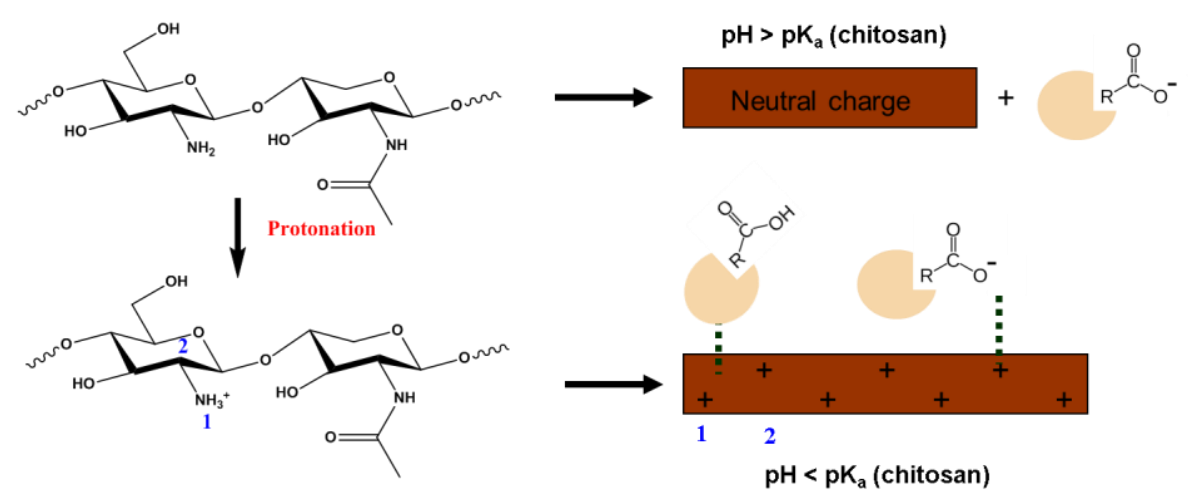

Scheme 1 An illustrative view of the chitosan biopolymer structure before (top) and after protonation (bottom), where its polar sites (1) and apolar sites (2) represent the potential adsorption sites for naphthenic acid fraction compounds (NAFCs). R denotes an apolar fragment of the naphthenate moiety with a variable carbon number and double-bond equivalent (DBE), where the dashed line refers to an adsorptive interaction at apolar or polar sites

\subsection{Double-bond Equivalents}

Figure 2A-B illustrates the trend in chitosan uptake of OSPW with variable double-bond equivalent (DBE) values for the $\mathrm{O}_{2}$ series of selected NAFCs at variable chitosan concentration. The DBE term relates to the degree of unsaturation that can be inferred as the number of ring systems by subtracting 1 from the DBE to estimate the number of rings (Bauer et al., 2015). DBE values between 3.5 and 4.5 were among the most abundant in the R-OSPW, where these species showed attenuated removal with increasing chitosan concentration. Similar observations were made on all DBE values except 1.5, implying that unsaturated NAFCs do not show favorable uptake with either acid additive $\left(\mathrm{HCl}\right.$ or $\left.\mathrm{CH}_{3} \mathrm{COOH}\right)$ in aqueous solution. Alternatively, the selective removal of NAFCs alters the ionization and hydration state of the 
naphthenate species, in line with the presence of chloride (due to $\mathrm{HCl}$ ) or acetate (due to AcA) counterions for each respective sample of NAFCs. The counterion effect is more pronounced when the concentration of chitosan is increased. In addition, the trend in uptake of the NAFCs with variable DBE values differ for the two acidified forms of chitosan. The trend in uptake of chitosan-AcA increases in the following order: $1.5<7.5<4.5<3.5 \approx 5.5 \approx 6.6 \approx 8.5<2.5$. In comparison, the trend in uptake of the naphthenates by the chitosan- $\mathrm{HCl}$ system adopt the following order for the $\mathrm{DBE}$ values: $1.5<7.5<3.5 \approx 4.5<2.5 \approx 5.5 \approx 6.5 \approx 8.5$.
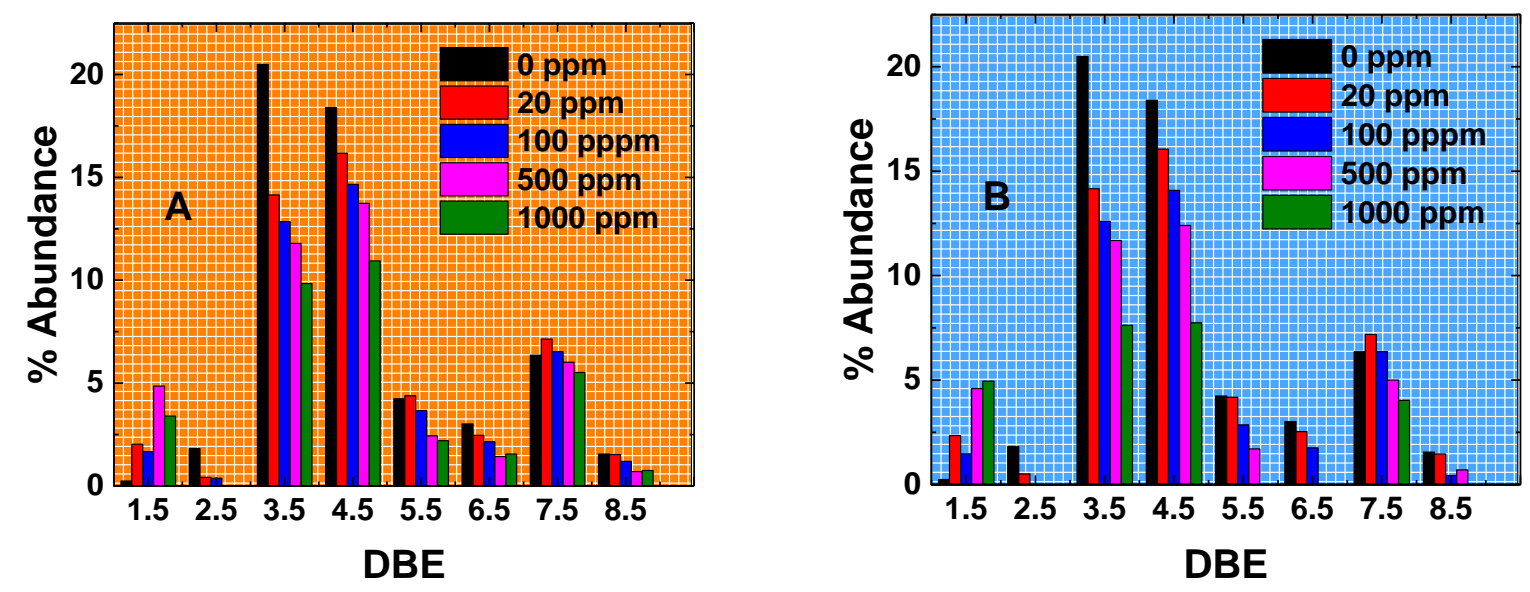

Figure 2 Trends in the chitosan uptakes of species with double-bond equivalents (DBEs) for the $\mathrm{O}_{2}$ series: chitosan-acetic acid (AcA) and B) chitosan-hydrochloric acid systems

The DBE results for the wetland treated samples are shown in Figure 3. Similar to previous results with raw OSPW, the chitosan- $\mathrm{HCl}$ system generally reveal greater uptake, where the amount removed was variable across the different types of naphthenates at similar chitosan concentration values. This trend may relate to the variable nature of the wetland treated samples, which contribute to different removal profiles of NAFCs that yield variable levels of sorption by chitosan, in accordance with the role of hydration and importance of hydrophobic effects for such types of chitosan systems (Mohamed et al., 2015a; Mohamed et al., 2015b).
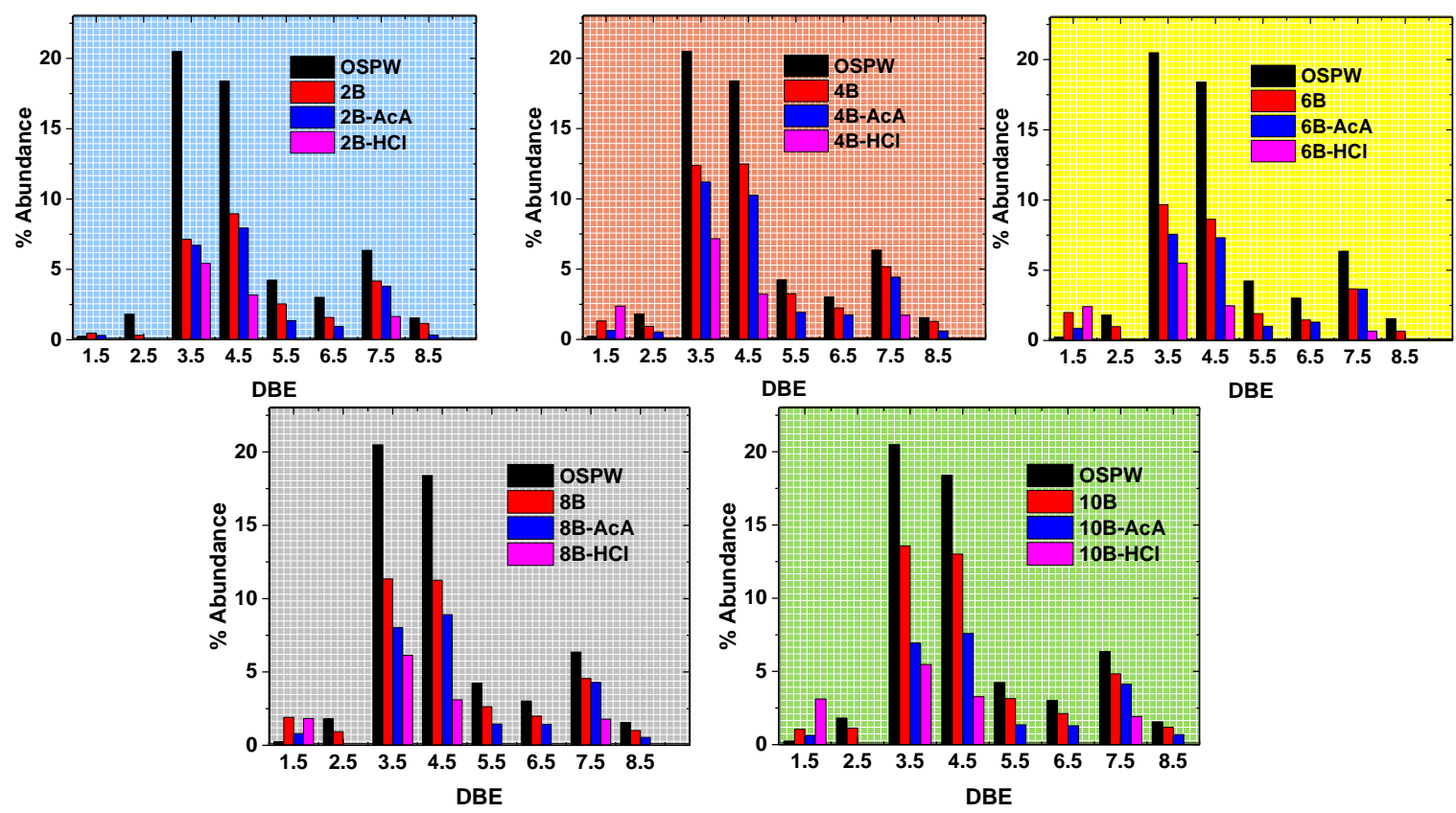

Figure 3 Double-bond equivalents (DBEs) of the $\mathrm{O}_{2}$ series for $2 \mathrm{~B}, 4 \mathrm{~B}, 6 \mathrm{~B}, 8 \mathrm{~B}$, and 10B 


\subsection{Ion class distribution}

The ion class distribution of species found in NAFCs before and after incubation with the chitosan materials are shown in Figure 4A-B. The most abundant species are those containing $\mathrm{O}_{2}$ species. The sorption properties of chitosan reveal an apparent discrimination among some of the naphthenate species, where chitosan sorbs $\mathrm{O}_{2}, \mathrm{O}_{3} \mathrm{~S}$, and $\mathrm{O}_{4} \mathrm{~S}$ but not the $\mathrm{O}_{3}, \mathrm{O}_{4}, \mathrm{O}_{3} \mathrm{~S}_{3}$, and $\mathrm{OS}_{4}$ series. The species that are removed from aqueous solution by chitosan show a similar trend, where the chitosan- $\mathrm{HCl}$ system has higher overall removal $(\%)$ as compared with chitosan-AcA. The variations in uptake in each respective acid solution reveal the key role of electrostatic interactions and counterion binding effects, as described above ( $c f$. Scheme 1).

Similar observations are noted in Figure 5 for the wetland treated samples in terms of the selective removal of various classes of naphthenates. Therein, variable levels of removal and discrimination are observed for the different types of wetland treated samples.

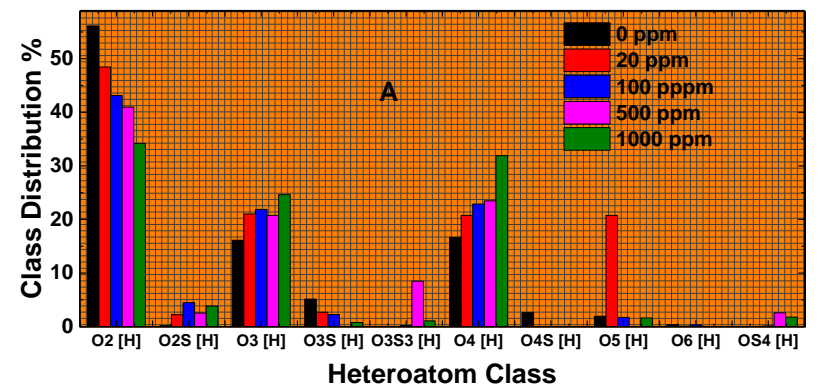

(a)

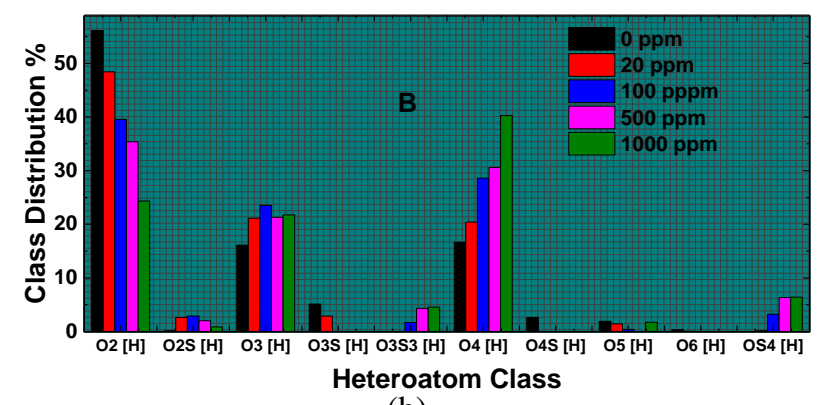

(b)

Figure 4 Ion class distribution data from electrospray ionization high-resolution mass spectrometry (ESI-HRMS) of A) chitosan-acetic acid (AcA) and B) chitosan- $\mathrm{HCl}$
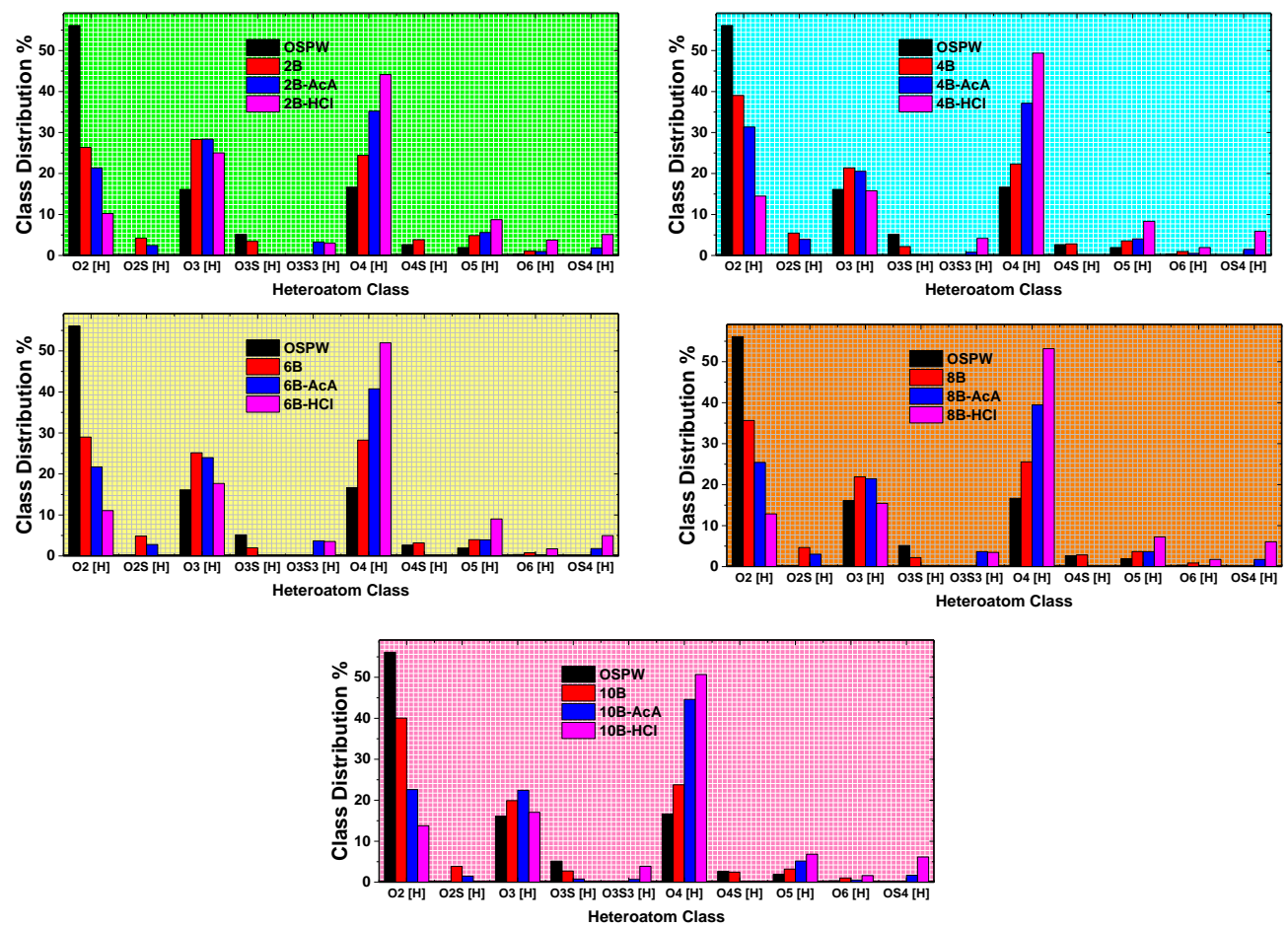

Figure 5 Ion class distribution data from electrospray ionization high-resolution mass spectrometry (ESI-HRMS) of 2B, 4B, 6B, 8B, and 10B 
To further reveal the complex interrelationship related to the variable uptake properties of the two different acidified forms of chitosan used for the treatment of sample $2 \mathrm{~B}$, three-dimensional (3-D plots of DBE and carbon number versus the abundance of residual naphthenates (intensity) are shown in Figure 6. For instance, the chitosan- $\mathrm{HCl}$ system reveals trends that reflect a greater discrimination or improved ionization efficiency for naphthenates with DBE values of 4.5 and 5.5 for carbon numbers of 12 and 13, along with DBE 8.5 for carbon numbers 16 and 17. The relative discrimination is observed to be lower for the chitosan- $\mathrm{HCl}$ system, where the effect likely relates to its overall higher uptake of the NAFCs. The trend is in agreement with the role of electrostatic interactions due to the counterion exchange effects described above, as well as the results described in Figure 1. By contrast, discrimination amongst NAFCs according to the DBE and carbon number is anticipated for systems governed by hydrophobic effects, as reported for cross-linked chitosan systems elsewhere (Mohamed et al., 2015a).

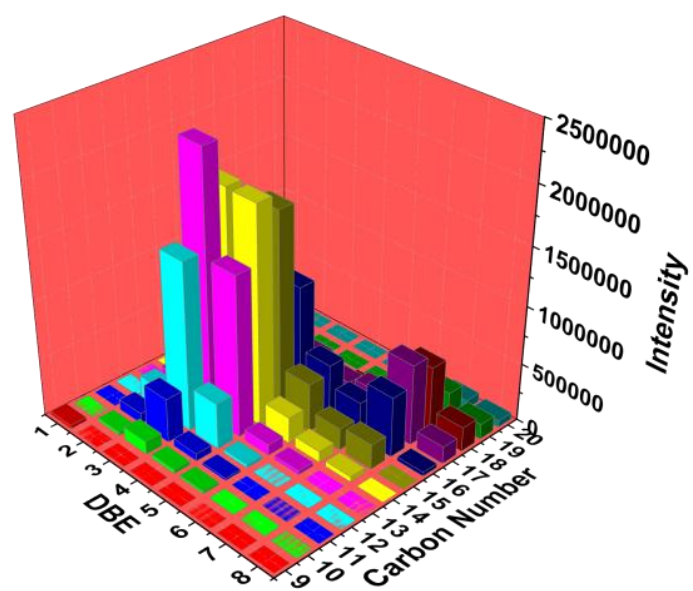

(a)

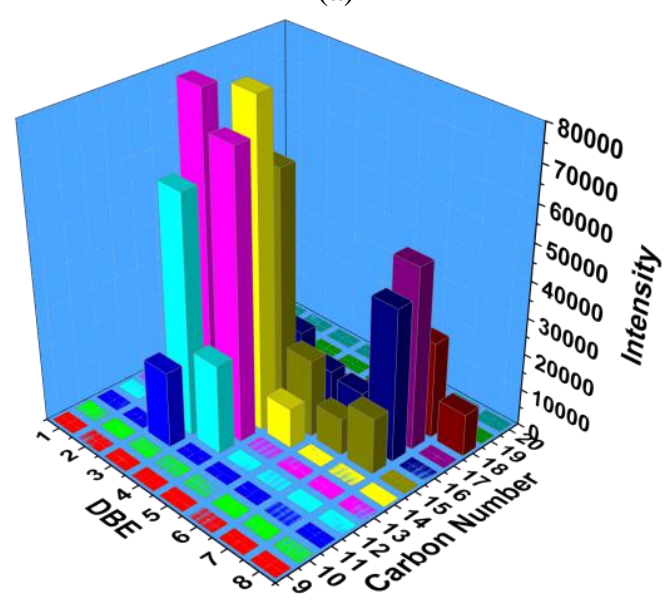

(c)

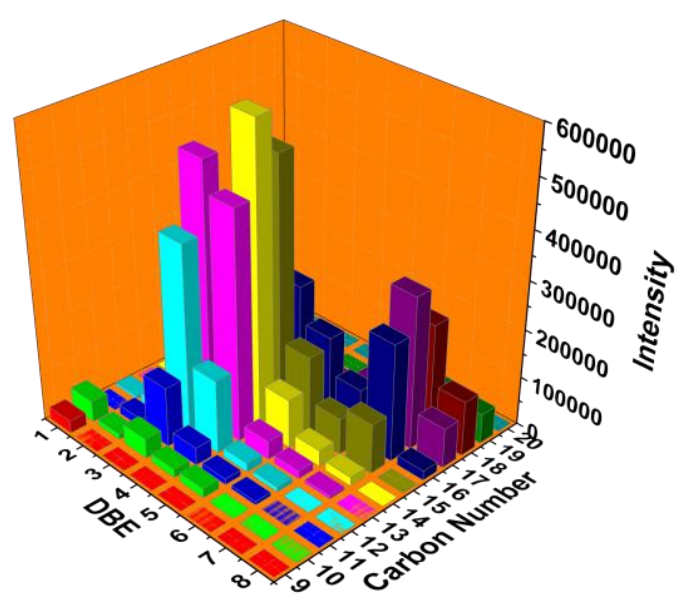

(b)

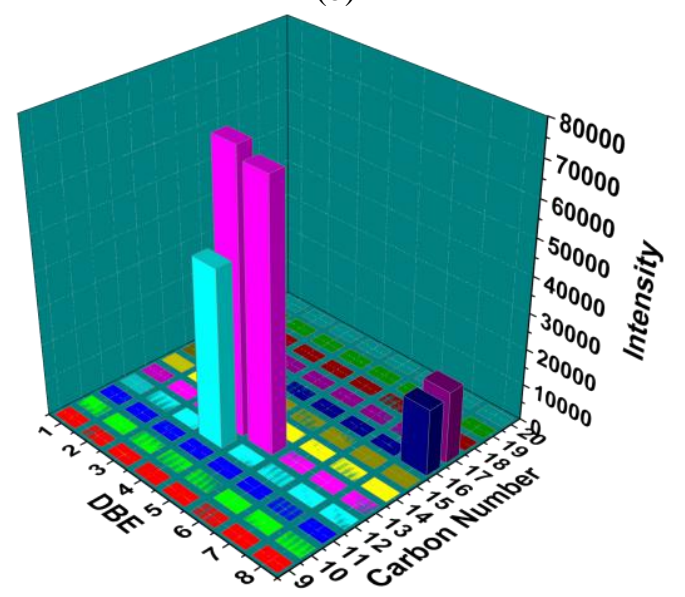

(d)

Figure 6 Three-dimensional (3D) plots for uptake of various oil sands process water (OSPW) samples: (a) raw OSPW (R-OSPW); (b) 2B; (c) 2B after incubating with 1,000 ppm chitosan-acetic acid (AcA); and (d) 2B after incubating with 1,000 ppm chitosan- $\mathrm{HCl}$

\section{CONCLUSION}

This study provides strong support for the key role of biopolymer hydration in adsorption and self-assembly processes (Dehabadi et al., 2018). Experimental support for the two hypotheses provides an account for the association of chitosan and NAFCs. Hypothesis $i$ was related to the enhanced adsorptive surface area of the biopolymer that occurred via solubilization of chitosan in aqueous acid, revealing an enhanced sequestration efficiency and molecular selectivity toward NAFCs in aqueous media. Hypothesis $i i$ accounted for the role of counterion hydration 
effects, in accordance with the differential uptake of NAFCs in conjunction with the use of different acid additives $\left(\mathrm{HCl}\right.$ and $\left.\mathrm{CH}_{3} \mathrm{COOH}\right)$. The removal capacity of NAFCs from OSPW (both raw and treated) by dissolution of chitosan into an acid solution resulted in substantially greater removal (1,000-fold) compared with a previous report on water-insoluble forms of chitosan-based sorbents (Mohamed et al., 2015a). The role of hydration effects due to chloride and acetate counterion binding with chitosan parallel the trends in lyotropy described by the Hofmeister effect for such anions, in agreement with the observed trends in uptake for NAFCs. The use of acid dopants with variable counterions (chloride versus acetate) to solubilize chitosan offers a new approach for tuning the structure-function properties of chitosan sorbents with organic anion (carboxylate) species, as revealed for ionized NAFCs. The adsorption method employed herein favors sequestration of $\mathrm{O}_{2}$-containing species, which are known to be the major cause of toxicity in OSPW (Mohamed et al., 2017). Furthermore, solubilized chitosan reveals that selective removal can be achieved in complex mixtures of naphthenates that suggest the role of ionization effects among species of NAFCs. The role of ionization effects are readily detected using electrospray mass spectrometry in negative ion mode but are not readily observed in raw and treated wetlands OSPW systems. The molecular level insight gained through this study is anticipated to contribute favorably to sustainable resource extraction and remediation of industrial tailings through the use of green chemistry and adsorption-based technology reported herein.

\section{ACKNOWLEDGEMENT}

The authors acknowledge the support provided by the Government of Canada (Natural Resources Canada) for this research.

\section{REFERENCES}

Ajaero, C., McMartin, D.W., Peru, K.M., Bailey, J., Haakensen, M., Friesen, V., Martz, R., Hughes, S. A., Brown, C., Chen, H., McKenna, A.M., Corilo, Y.E., Headley, J.V. 2017. Fourier Transform Ion Cyclotron Resonance Mass Spectrometry Characterization of Athabasca Oil Sand Process-Affected Waters Incubated in the Presence of Wetland Plants. Energy \& Fuels, Volume 31(2), pp. 1731-1740

Ajaero, C., Peru, K.M., Simair, M., Friesen, V., O'Sullivan, G., Hughes, S.A., McMartin, D.W., Headley, J.V. 2018. Fate and Behavior of Oil Sands Naphthenic Acids in a Pilot-scale Treatment Wetland as Characterized by Negative-ion Electrospray Ionization Orbitrap Mass Spectrometry. Science of the Total Environment, Volume 631-632, pp. 829-839

Allen, E.W. 2008. Process Water Treatment in Canada's Oil Sands Industry: I. Target Pollutants and Treatment Objectives. Journal of Environmental Engineering and Science, Volume 7(2), pp. 123-138

Armstrong, S.A., Headley, J.V., Peru, K.M., Germida, J.J. 2009. Differences in Phytotoxicity and Dissipation between Ionized and Nonionized Oil Sands Naphthenic Acids in Wetland Plants. Environmental Toxicology and Chemistry, Volume 28(10), pp. 2167-2174

Barrow, M.P., Witt, M., Headley, J.V., Peru, K.M. 2010. Athabasca Oil Sands Process Water: Characterization by Atmospheric Pressure Photoionization and Electrospray Ionization Fourier Transform Ion Cyclotron Resonance Mass Spectrometry. Analytical Chemistry, Volume 82(9), pp. 3727-3735

Bauer, A.E., Frank, R.A., Headley, J.V., Peru, K.M., Hewitt, L.M., Dixon, D.G. 2015. Enhanced characterization of oil sands acid-extractable organics fractions using electrospray ionization-high-resolution mass spectrometry and synchronous fluorescence spectroscopy. Environmental Toxicology and Chemistry, Volume 34(5), pp. 1001-1008 
Bhalkaran, S., Wilson, L. 2016. Investigation of Self-Assembly Processes for Chitosan-based Coagulant-Flocculant Systems: A Mini-review. International Journal of Molecular Sciences, Volume 17(10), pp. 1662-1683

Clemente, J.S., Fedorak, P.M. 2005. A Review of the Occurrence, Analyses, Toxicity, and Biodegradation of Naphthenic Acids. Chemosphere, Volume 60(5), pp. 585-600

Crini, G. 2005. Recent Developments in Polysaccharide-based Materials Used as Adsorbents in Wastewater Treatment. Progress in Polymer Science, Volume 30(1), pp. 38-70

Dehabadi, L., Karoyo, A.H., Wilson, L.D. 2018. Spectroscopic and Thermodynamic Study of Biopolymer Adsorption Phenomena in Heterogeneous Solid-Liquid Systems. ACS Omega, Volume 3(11), pp. 15370-15379

Eftaiha, A.F., Alsoubani, F., Assaf, K.I., Troll, C., Rieger, B., Khaled, A.H., Qaroush, A.K. 2016. An investigation of carbon dioxide capture by chitin acetate/DMSO binary system. Carbohydrate Polymers, Volume 152, pp.163-169

Faulwetter, J.L., Gagnon, V., Sundberg, C., Chazarenc, F., Burr, M.D., Brisson, J., Camper, A.K., Stein, O.R. 2009. Microbial Processes Influencing Performance of Treatment Wetlands: A Review. Ecological Engineering, Volume 35(6), pp. 987-1004

Giesy, J.P., Anderson, J.C., Wiseman, S.B. 2010. Alberta Oil Sands Development. Proceedings of the National Academy of Sciences, Volume 107(3), pp. 951-952

Grewer, D.M., Young, R.F., Whittal, R.M., Fedorak, P.M. 2010. Naphthenic Acids and Other Acid-extractables in Water Samples from Alberta: What is Being Measured? Science of the Total Environment, Volume 408(23), pp. 5997-6010

Haakensen, M., Pittet, V., Spacil, M.M., Castle, J.W., Rogers Jr., J.H., 2015. Key Aspects for Successful Design and Implementation of Passive Water Treatment Systems. Journal of Environmental Solutions for Oil, Gas, and Mining, Volume 1(1), pp. 59-81

Headley, J.V., McMartin, D.W., 2004. A Review of the Occurrence and Fate of Naphthenic Acids in Aquatic Environments. Journal of Environmental Science and Health, Part A: Toxic/Hazardous Substances \& Environmental Engineering, Volume 39(8), pp. 1989-2010 Headley, J.V., Peru, K.M., Armstrong, S.A., Han, X., Martin, J.W., Mapolelo, M.M., Smith, D.F., Rogers, R.P., Marshall, A.G. 2009. Aquatic Plant-derived Changes in Oil Sands Naphthenic Acid Signatures Determined by Low-, High- and Ultrahigh-resolution Mass Spectrometry. Rapid Communications in Mass Spectrometry, Volume 23(4), pp. 515-522

Headley, J.V., Peru, K.M., Barrow, M.P. 2016. Advances in Mass Spectrometric Characterization of Naphthenic Acids Fraction Compounds in Oil Sands Environmental Samples and Crude Oil-A Review. Mass Spectrometry Reviews, Volume 35(2), pp. 311328

Hofmeister, F., 1888. Zur Lehre von der Wirkung der Salze. Archiv für experimentelle Pathologie und Pharmakologie, Volume 25(4-5), pp. 247-260

Huang, R., Sun, N., Chelme-Ayala, P., McPhedran, K.N., Changalov, M., Gamal El-Din, M. 2015. Fractionation of Oil Sands-process Affected Water Using pH-dependent Extractions: A Study of Dissociation Constants for Naphthenic Acids Species. Chemosphere, Volume 127, pp. 291-296

Hughes, S.A., Huang, R., Mahaffey, A., Chelme-Ayala, P., Klamerth, N., Meshref, M.N.A., Ibrahim, M.D., Brown, C., Peru, K.M., Headley, J.V., Gamal El-Din, M. 2017. Comparison of Methods for Determination of Total Oil Sands-derived Naphthenic Acids in Water Samples. Chemosphere, Volume 187, pp. 376-384

Jungwirth, P., Cremer, P.S., 2014. Beyond Hofmeister. Nature Chemistry, Volume 6, pp. 261263

Kadlec, R.H., Wallace, S. 2008. Treatment Wetlands, CRC Press, Boca Raton, FL.

Kelly, E.N., Schindler, D.W., Hodson, P.V., Short, J.W., Radmanovich, R., Nielsen, C.C. 2010. Oil sands development contributes elements toxic at low concentrations to the Athabasca 
River and its tributaries. Proceedings of the National Academy of Sciences, Volume 107(37), pp. 16178-16183

Kong, A.Q., Ji, Y.H., Ma, H.H., Song, Y.F., He, B.Q., Li, J.X. 2018. A Novel Route for the Removal of $\mathrm{Cu}(\mathrm{II})$ and $\mathrm{Ni}(\mathrm{II})$ Ions via Homogeneous Adsorption by Chitosan Solution. Journal of Cleaner Production, Volume 192, pp. 801-808

Limited, S.C. 2014. Oil Sands Performance Report 2014, Shell Canada Ltd., Calgary, AB, Canada.

Mahaninia, M.H., Wilson, L.D. 2017. Phosphate Uptake Studies of Cross-linked Chitosan Bead Materials. Journal of Colloid and Interface Science, Volume 485, pp. 201-212

McQueen, A.D., Kinley, C.M., Kiekhaefer, R.L., Calomeni, A.J., Rodgers, J.H., Castle, J.W., 2016. Photocatalysis of a Commercial Naphthenic Acid in Water Using Fixed-Film $\mathrm{TiO}_{2}$. Water, Air, \& Soil Pollution, Volume 227(132), pp. 1-11

Mohamed, M.H., Peru, K., Headley, J., Wilson, L.D., 2017. Chitosan Biopolymers for Analysis of Organic Acids in Aquatic Environments of Treatment Wetlands. Journal of Geoscience and Environment Protection, Volume 5, pp. 214-225

Mohamed, M.H., Udoetok, I.A., Wilson, L.D., Headley, J.V. 2015a. Fractionation of Carboxylate Anions from Aqueous Solution Using Chitosan Cross-linked Sorbent Materials. RSC Advances, Volume 5, pp. 82065-82077

Mohamed, M.H., Wilson, L.D., Headley, J.V. 2013. Tunable Polymeric Sorbent Materials for Fractionation of Model Naphthenates. The Journal of Physical Chemistry B, Volume 117(13), pp. 3659-3666

Mohamed, M.H., Wilson, L.D., Headley, J.V., Peru, K.M. 2011. Sequestration of Naphthenic Acids from Aqueous Solution Using $\beta$-Cyclodextrin-based Polyurethanes. Physical Chemistry Chemical Physics, Volume 13(3), pp. 1112-1122

Mohamed, M.H., Wilson, L.D., Shah, J.R., Bailey, J., Peru, K.M., Headley, J.V. 2015b. A Novel Solid-state Fractionation of Naphthenic Acid Fraction Components from Oil Sands Process-affected Water. Chemosphere, Volume 136, pp. 252-258

Morandi, G.D., Wiseman, S.B., Pereira, A., Mankidy, R., Gault, I.G.M., Martin, J.W., Giesy, J.P. 2015. Effects-directed Analysis of Dissolved Organic Compounds in Oil Sands Process-affected Water. Environmental Science \& Technology, Volume 49(20), pp. 1239512404

Pramanik, S. 2016. Review of Biological Processes in Oil Sands: A Feasible Solution for Tailings Water Treatment. Environmental Reviews, Volume 24(3), pp. 274-284

Renault, F., Sancey, B., Badot, P.M., Crini, G. 2009. Chitosan for Coagulation/Flocculation Processes-An Eco-friendly Approach. European Polymer Journal, Volume 45(5), pp. $1337-1348$

Roberts, G.A.F. 1992. Chemical Behaviour of Chitin and Chitosan. In: Chitin Chemistry, pp. 203-273, Macmillan Education UK, London

Rodgers, J.J.H., Castle, J.W. 2008. Constructed Wetland Systems for Efficient and Effective Treatment of Contaminated Waters for Reuse. Environmental Geosciences, Volume 15(1), pp. $1-8$

Udoetok, I.A., Wilson, L.D., Headley, J.V. 2016. Quaternized Cellulose Hydrogels as Sorbent Materials and Pickering Emulsion Stabilizing Agents. Materials, Volume 9(8), pp. 645

Valipour, A., Ahn, Y.-H. 2016. Constructed Wetlands as Sustainable Ecotechnologies in Decentralization Practices: A Review. Environmental Science and Pollution Research, Volume 23(1), 180-197

Wilson, L.D., Mohamed, M.H. Headley, J.V. 2014. Novel materials for environmental remediation of oil sands contaminants, Reviews of Environmental Health Volume 29(1-2), pp. 5-8 